\title{
Dysregulation of Circulating miR-24-3p in Children with Obesity and Its Predictive Value for Metabolic Syndrome
}

\author{
Bingjin Zhang $^{\text {a Lingling Xing }}{ }^{b}$ Beibei Wang ${ }^{c}$ \\ aDepartment of Paediatrics, Shengli Oilfield Central Hospital, Dongying, China; ${ }^{b}$ Department of Paediatrics, Dongying District \\ People's Hospital, Dongying, China; 'Department of Endocrinology, Shengli Oilfield Central Hospital, Dongying, China
}

\section{Keywords}

Metabolic syndrome · Obesity · MiR-24-3p · Diagnosis

\begin{abstract}
Introduction: Obesity is a major risk factor for metabolic disorders in children. Therefore, it is particularly important to study the abnormal regulation of circulating miR-24-3p in obese children and its predictive value for metabolic syndrome. Methods: Serum samples were obtained from children with obesity $(n=45)$, obese children with metabolic syndrome $(n=52)$, and healthy controls $(n=50)$. The expression levels of miR-24-3p were detected by reverse transcription quantitative PCR. The ROC curve was used to evaluate the diagnostic value of miR-24-3p. Pearson's correlation analysis was performed to evaluate the relationship between serum miR-24-3p and different clinical parameters. Logistic regression analysis was used to evaluate the relationship between miR-24-3p and obesity with metabolic syndrome in children. Results: The expression of miR-24-3p was the highest in obese children with metabolic syndrome. ROC results showed that miR-24-3p had the ability to distinguish healthy individuals from obese children (area under the curve $[A \cup C]=0.951$ ) and can predict the occurrence of metabolic syndrome for obese children (AUC $=0.890)$. The
\end{abstract}

expression level of miR-24-3p was positively correlated with body mass index $(r=0.817, p<0.001)$, fasting blood glucose $(r=0.798, p<0.001)$, triglycerides $(r=0.773, p<0.001)$, systolic blood pressure $(r=0.746, p<0.001)$, and diastolic blood pressure ( $r=0.623, p<0.001)$, respectively. Logistic regression analysis showed that miR-24-3p was an independent influence factor for the occurrence of metabolic syndrome in obese children. Discussion/Conclusion: MiR-24-3p is a potential noninvasive marker for children with obesity and has predictive value for the occurrence of metabolic syndrome.

(c) 2021 The Author(s)

Published by S. Karger AG, Basel

\section{Introduction}

Childhood obesity is an epidemic worldwide and has become a major public health problem. It is reported that the global prevalence of overweight and obesity in children has increased by more than $50 \%$ over the past 20 years and is expected to reach $9.1 \%$ by 2020 [1]. Childhood obesity can cause a range of complications, such as insulin resistance, hypertension, lipid metabolism disorder, and hyperinsulinemia [2], Therefore, to explore the

Bingjin Zhang and Lingling Xing contributed equally to this work. karger@karger.com www.karger.com/ofa

Karger $\stackrel{\text { ' }}{5}$

GOPEN ACCESS
(C) 2021 The Author(s)

Published by S. Karger AG, Basel

This is an Open Access article licensed under the Creative Commons Attribution-NonCommercial-4.0 International License (CC BY-NC) (http://www.karger.com/Services/OpenAccessLicense), applicable to the online version of the article only. Usage and distribution for commercial purposes requires written permission.
Correspondence to:

Beibei Wang, wangbeibei390@163.com 
pathogenesis of obesity and its complications has become one of the important research directions in pediatrics. Furthermore, the prevention and treatment of childhood obesity can prevent adult obesity and metabolic syndrome [3]. At the current time, metabolic syndrome in adults is widely understood. In contrast, little is known about the epidemiology and pathophysiology of metabolic syndrome in children [4].

MicroRNAs (miRNAs) regulate gene expression by binding to a complementary sequence of miRNA [5]. The disorder of miRNA expression affects gene expression, thus affecting cell function in the pathological process [6]. Identifying miRNAs with abnormal expression in tissue or serum is important for early diagnosis and treatment of the disease, including obesity [7]. For example, Dong et al. [8] identified miR-182 as a new negative regulator of fat formation and a potential therapeutic target for obesity. In addition, Garavelli et al. [9] reported that miR24-3p is upregulated in the progression of type 1 diabetes. Many investigations reported that obesity is associated with a series of metabolic syndrome, of which diabetes is one of the main complications [10]. However, there has been no literature on the association of miR-24-3p with childhood obesity and metabolic syndrome. According to the research progress, this work mainly studies the expression level of miR-24-3p in children with obesity and discusses the predictive value of miR-24-3p for metabolic syndrome in obese children.

\section{Materials and Methods}

\section{Clinical Sample Collection}

This study was approved by the Research Ethics Committee of Shengli Oilfield Central Hospital (2018045). Subjects and legal guardians were informed of the purpose and procedure of the study, and written informed consent was obtained from legal guardians. The research was conducted ethically in accordance with the World Medical Association Declaration of Helsinki.

The children were recruited from Shengli Oilfield Central Hospital, who were aged from 1 to $<17$ years [11]. Besides, obese children were recruited without the following conditions [12]: (1) children using any chronic medication, (2) self-reported type 1 diabetes mellitus, (3) renal disease, and (4) cancer. In children, obesity was defined as body mass index (BMI) $\geq 95$-hundredths using the childhood date of Working Group on Obesity in China (WGOC) [13]. On the basis of obese children, any of the following 2 points can be identified as having metabolic syndrome [14]: (1) fasting blood glucose $\geq 5.6 \mathrm{mmol} / \mathrm{L}$ or type 2 diabetes; (2) systolic blood pressure $\geq 130 \mathrm{~mm} \mathrm{Hg}$ and/or diastolic blood pressure $\geq 85 \mathrm{~mm}$ $\mathrm{Hg}$; (3) triglyceride $\geq 1.7 \mathrm{mmol} / \mathrm{L}$; and (4) high-density lipoprotein cholesterol $(<1.03 \mathrm{mmol} / \mathrm{L})$.

On the basis of a $5 \%$ false-positive error rate (alpha $=0.05$, 2 -sided) and $90 \%$ power (beta $=0.1$ ), the sample size was estimat- ed using PASS11 software. A sample size of at least 35 participants should be recruited in each group. Therefore, a total of 97 children aged 6-16 years were recruited for this study and were divided into 2 groups according to the condition of metabolic syndrome: 45 cases in the obesity group (11.58 \pm 3.17 years old, $21 / 24$ male/female) and 52 cases in the obesity with metabolic syndrome (10.92 \pm 2.93 years, $22 / 30$ male/female). Another 50 healthy children with normal weight served as a control group $(10.30 \pm 2.85$ years, $24 / 26$ male/female). Blood samples were collected between 8 and 9 o'clock in the evening during fasting to avoid different circadian changes. Triglycerides (TG) and total cholesterol (TC) were measured by enzymatic and cholesterol oxidase methods, respectively, and HDL and low-density lipoprotein (LDL) were both detected by using the direct assay method. Fasting blood glucose (FBG) levels were determined by enzyme diagnostic GmbH (GLU, Roche Diagnostics GmbH, Mannheim, Germany).

RNA Extraction and Reverse Transcription-Quantitative PCR

Total RNA was extracted from serum samples using TRIzol reagent (DIR, 15596018, Invitrogen; Thermo Fisher Scientific, Inc.) according to the manufacturer's protocol. Reverse transcription was performed using a Script RT kit (205311, Qiagen GmbH), and the conditions were $37^{\circ} \mathrm{C}$ for $15 \mathrm{~min}$ and $98^{\circ} \mathrm{C}$ for $5 \mathrm{~min}$. SYBR Green I Master Mix kit (DIR, RR420A, Invitrogen; Thermo Fisher Scientific, Inc.) was used for reverse transcription quantitative PCR (RT-qPCR) to investigate miR-24-3p expression levels. The following thermocycling conditions were used for the PCR: initial denaturation at $95^{\circ} \mathrm{C}$ for $5 \mathrm{~min} ; 30$ cycles of $95^{\circ} \mathrm{C}$ for $30 \mathrm{~s}, 60^{\circ} \mathrm{C}$ for $30 \mathrm{~s}$, and $72^{\circ} \mathrm{C}$ for $20 \mathrm{~s}$; and a final extension at $72^{\circ} \mathrm{C}$ for $10 \mathrm{~min}$. U6 was used as an internal reference for data normalization of miR-24-3p expression levels. The relative expression levels of miR24-3p were determined with U6 using the $2^{-\Delta \Delta \mathrm{Ct}}$ method.

\section{Statistical Analysis}

All data in this study were statistically analyzed by GraphPad Prism 6.0 software and SPSS21.0 software and represented by the mean and standard deviation. Student's $t$-test was used to compare the statistical differences of continuous variables between the 2 groups, and the $\chi^{2}$ test was used to examine gender differences between the 2 groups. One-way ANOVA was used to analyze and compare the statistical differences between different groups. The ROC curve was used to evaluate the diagnostic value of miR-24-3p. Pearson correlation analysis was used to detect the correlation between miRNA and clinical indicators. Logistic regression analysis was used to evaluate the relationship between each variable and the occurrence of obesity metabolic syndrome. $p<0.05$ was considered statistically significant.

\section{Results}

\section{Clinical Characteristics of Different Study Groups}

Compared with the control group, BMI, FBG, TG, systolic blood pressure (SBP), and diastolic blood pressure (DBP) were all higher than that in the obese group and the metabolic syndrome group. In addition, BMI, FBG, TG, SBP, and DBP in the metabolic syndrome group were 
Table 1. Clinical data of the study population

\begin{tabular}{lcccc}
\hline Parameter & $\begin{array}{l}\text { Control } \\
(n=50)\end{array}$ & $\begin{array}{l}\text { Obesity } \\
(n=45)\end{array}$ & $\begin{array}{l}\text { Obesity with meta- } p \text { value } \\
\text { bolic syndrome } \\
(n=52)\end{array}$ & \\
\hline$N$ (male and female) & $50(24 / 26)$ & $45(21 / 24)$ & $52(22 / 30)$ & 0.834 \\
Age, years & $10.30 \pm 2.85$ & $11.58 \pm 3.17$ & $10.92 \pm 2.93$ & 0.117 \\
$\mathrm{BMI}, \mathrm{kg} / \mathrm{m}^{2}$ & $15.22 \pm 1.74$ & $17.50 \pm 2.16$ & $23.09 \pm 2.19$ & 0.000 \\
$\mathrm{FBG}, \mathrm{mmol} / \mathrm{L}$ & $5.00 \pm 0.61$ & $5.33 \pm 0.84$ & $6.06 \pm 0.56$ & 0.000 \\
$\mathrm{TG}, \mathrm{mmol} / \mathrm{L}$ & $0.92 \pm 0.09$ & $1.21 \pm 0.05$ & $1.35 \pm 0.07$ & 0.000 \\
$\mathrm{TC}, \mathrm{mmol} / \mathrm{L}$ & $3.97 \pm 0.56$ & $3.98 \pm 0.52$ & $4.15 \pm 0.54$ & 0.191 \\
$\mathrm{LDL}, \mathrm{mmol} / \mathrm{L}$ & $2.32 \pm 0.62$ & $2.38 \pm 0.52$ & $2.34 \pm 0.57$ & 0.898 \\
$\mathrm{HDL}, \mathrm{mmol} / \mathrm{L}$ & $2.00 \pm 0.52$ & $1.90 \pm 0.57$ & $1.87 \pm 0.60$ & 0.419 \\
$\mathrm{SBP}, \mathrm{mm} \mathrm{Hg}$ & $107.80 \pm 11.36$ & $118.94 \pm 4.36$ & $128.39 \pm 7.16$ & 0.000 \\
$\mathrm{DBP}, \mathrm{mm} \mathrm{Hg}$ & $70.16 \pm 6.44$ & $78.32 \pm 4.51$ & $87.09 \pm 9.07$ & 0.000 \\
\hline
\end{tabular}

BMI, body mass index; FBG, fasting blood glucose; TG, triglycerides; TC, total cholesterol; HDL, high-density lipoprotein; LDL, low-density lipoprotein; SBP, systolic blood pressure; DBP, diastolic blood pressure; SD, standard deviation. Data are expressed as $n$ or mean $\pm \mathrm{SD}$. higher than those in the obesity group. There was no statistical difference in the age, gender, TC, LDL, and HDL among the 3 groups, as shown in Table 1 .

\section{Expression Levels of miR-24-3p in Different Study Groups}

The expression level of miR-24-3p in the serum of the children was detected by RT-qPCR. The results of this study are shown in Figure 1. The expression level of miR$24-3 p$ in the serum of obese children was significantly higher than that of healthy controls $(p<0.001)$. In addition, the present study also found that miR-24-3p expression levels were significantly higher in obese children with metabolic syndrome than those in obese children ( $p$ $<0.001)$. Notably, obese children with metabolic syndrome had the highest levels of expression compared with the other 2 groups. The results suggest that miR-24$3 p$ may be a key biomolecule in obese children and play an important biological role in the disease progression.

\section{Diagnostic Value of miR-24-3p in Children with Obesity}

Figure 2A shows the diagnostic value analysis of serum miR-24-3p in obese children. As can be seen from the figure, when the cutoff was 1.255 , the area under the curve of miR-24-3p was 0.951 , the sensitivity was $91.0 \%$, and the specificity was $90.0 \%$. We presume that miR-24$3 p$ has the ability to distinguish between obese children and healthy individuals. Figure $2 \mathrm{~B}$ shows the diagnostic value analysis of serum miR-24-3p for obese children with metabolic syndrome. According to the expression

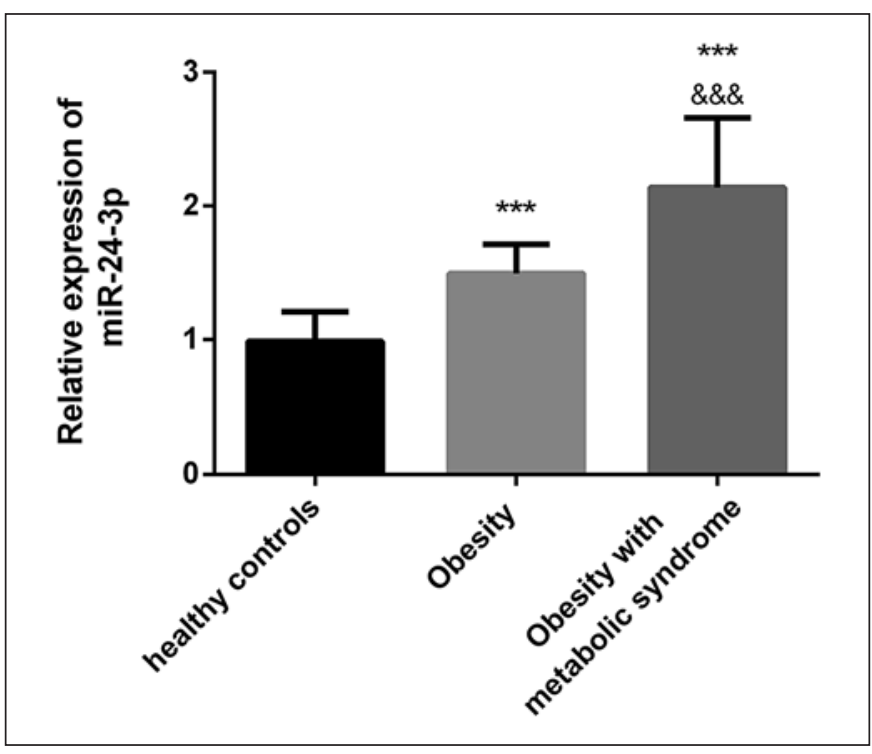

Fig. 1. Expression levels of miR-24-3p in different groups were detected by RT-qPCR. miR-24-3p expression levels were significantly increased in obese children with metabolic syndrome compared with healthy children and obese children without metabolic syndrome. Compared with healthy controls, ${ }^{* * *} p<0.001$; compared with obese children without metabolic syndrome, ${ }^{\& \& \&} p<0.001$. RT-qPCR, reverse transcription quantitative PCR.

level of miR-24-3p in obese children and obese children with metabolic syndrome, the ROC curve was drawn to evaluate the diagnostic value of miR-24-3p in obese children with metabolic syndrome. As shown in Figure 2B, the expression of miR-24-3p may be used to distinguish 


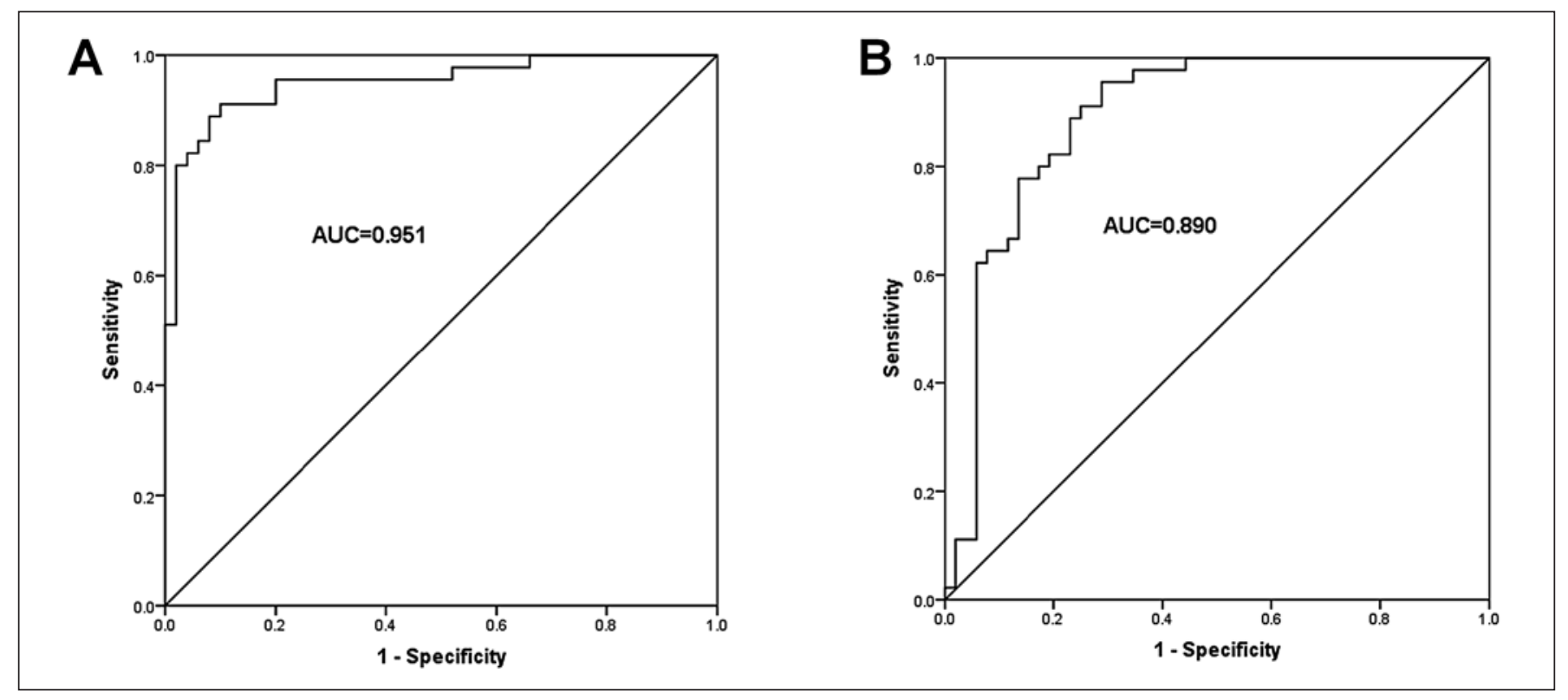

Fig. 2. ROC curves were established to assess the ability of miR-24-3p to differentiate between healthy individuals and obese children without metabolic syndrome. A The area under the curve was 0.951 , the sensitivity was $91.0 \%$, the specificity was $90.0 \%$, and the cutoff value was 1.256 . B To evaluate the differentiation ability of miR24-3p for obese children with or without metabolic syndrome, the area under the curve was 0.890 , the sensitivity was $95.6 \%$, the specificity was $71.2 \%$, and the cutoff value was 1.832 . AUC, area under the curve.

Table 2. Correlation between miR-24-3p and various indicators

\begin{tabular}{lcr}
\hline Parameter & $\begin{array}{l}\text { Correlation with } \\
\text { miR-24-3p }(r)\end{array}$ & $p$ value \\
\hline $\mathrm{BMI}, \mathrm{kg} / \mathrm{m}^{2}$ & 0.817 & $<0.001$ \\
$\mathrm{FBG}, \mathrm{mmol} / \mathrm{L}$ & 0.798 & $<0.001$ \\
$\mathrm{TG}, \mathrm{mmol} / \mathrm{L}$ & 0.773 & $<0.001$ \\
$\mathrm{TC}, \mathrm{mmol} / \mathrm{L}$ & 0.142 & 0.164 \\
$\mathrm{LDL}, \mathrm{mmol} / \mathrm{L}$ & 0.123 & 0.230 \\
$\mathrm{HDL}, \mathrm{mmol} / \mathrm{L}$ & -0.37 & 0.722 \\
$\mathrm{SBP}, \mathrm{mm} \mathrm{Hg}$ & 0.746 & $<0.001$ \\
$\mathrm{DBP}, \mathrm{mm} \mathrm{Hg}$ & 0.623 & $<0.001$ \\
\hline
\end{tabular}

BMI, body mass index; FBG, fasting blood glucose; TG, triglycerides; TC, total cholesterol; HDL, high-density lipoprotein; LDL, low-density lipoprotein; SBP, systolic blood pressure; DBP, diastolic blood pressure; data are expressed as $r$.

obese children from obese children with metabolic syndrome. The area under the curve was 0.890 , the cutoff value was 1.832 , the sensitivity was $95.6 \%$, and the specificity was $71.2 \%$. The results of this study confirmed that $\mathrm{miR}-24-3 \mathrm{p}$ has a certain diagnostic value in differentiating children with obesity from those with metabolic syndrome.

MiR-24-3p in Obese Children with Metabolic Syndrome
Table 3. Association of different variables with the occurrence of obesity with metabolic syndrome

\begin{tabular}{llll}
\hline Variable & OR & $95 \% \mathrm{CI}$ & $p$ value \\
\hline MiR-24-3p & 2.874 & $1.074-7.692$ & 0.036 \\
Gender & 0.591 & $0.235-1.487$ & 0.264 \\
Age, years & 0.974 & $0.401-2.369$ & 0.954 \\
$\mathrm{BMI}, \mathrm{kg} / \mathrm{m}^{2}$ & 2.603 & $0.995-6.812$ & 0.051 \\
$\mathrm{FBG}, \mathrm{mmol} / \mathrm{L}$ & 1.402 & $0.577-3.406$ & 0.456 \\
$\mathrm{TG}, \mathrm{mmol} / \mathrm{L}$ & 1.247 & $0.507-3.065$ & 0.631 \\
$\mathrm{TC}, \mathrm{mmol} / \mathrm{L}$ & 1.248 & $0.522-2.980$ & 0.618 \\
$\mathrm{LDL}, \mathrm{mmol} / \mathrm{L}$ & 1.509 & $0.617-3.686$ & 0.367 \\
$\mathrm{HDL}, \mathrm{mmol} / \mathrm{L}$ & 0.752 & $0.315-1.797$ & 0.522 \\
$\mathrm{SBP}, \mathrm{mm} \mathrm{Hg}$ & 1.084 & $0.452-2.601$ & 0.856 \\
$\mathrm{DBP}, \mathrm{mm} \mathrm{Hg}$ & 1.660 & $0.667-4.135$ & 0.276 \\
\hline
\end{tabular}

BMI, body mass index; FBG, fasting blood glucose; TG, triglycerides; TC, total cholesterol; HDL, high-density lipoprotein; LDL, low-density lipoprotein; SBP, systolic blood pressure; DBP, diastolic blood pressure.

\section{Correlation between miR-24-3p and Various Indicators}

Pearson's correlation analysis used miRNA expression data from RT-qPCR to evaluate the relationship between serum miR-24-3p and different clinical parameters. As shown in Table 2, in obese children with or without met- 
abolic syndrome, serum miR-24-3p was positively correlated with BMI $(r=0.817, p<0.001)$, FBG $(r=0.798, p<$ $0.001)$, TG $(r=0.773, p<0.001), \operatorname{SBP}(r=0.746, p<0.001)$, and DBP $(r=0.623, p<0.001)$ but not correlated with TC $(r=0.142, p>0.05)$, LDL $(r=0.123, p>0.05)$, and HDL $(r=-0.37, p>0.05)$. We concluded that miR-24-3p might be associated with the occurrence of metabolic syndrome in obese children.

\section{Correlation between miR-24-3p Expression and the \\ Incidence of Metabolic Syndrome}

Table 3 uses logistic regression analysis to evaluate the relationship between miR-24-3p and obese children with metabolic syndrome. As can be seen from Table 3, serum $\mathrm{miR}-24-3 \mathrm{p}(\mathrm{OR}=2.874,95 \% \mathrm{CI}=1.074-7.692, p=0.036)$ was an independent factor for the occurrence of metabolic syndrome in obese children. In summary, miR-24$3 p$ may be a good indicator for evaluating obese children with metabolic syndrome.

\section{Discussion/Conclusion}

Childhood obesity is the result of a combination of genetic and environmental factors and has become a serious health problem. In recent years, the obesity rate of children and adolescents is increasing year by year. The prevention and treatment of childhood obesity can stop adult obesity and prevent adult metabolic syndrome, which is an urgent task and a long-term and difficult process [15]. Childhood obesity and metabolic syndrome may be mutually causal, constituting a vicious circle of serious harm to health.

The early prevention and treatment effect of obesity in children is better than that of adults, so the early diagnosis and timely intervene of childhood obesity is efficient against the evolution of metabolic syndrome. Finding and studying new genes related to obesity will open up new ideas for the prevention and treatment of metabolic syndrome caused by obesity.

Metabolic syndrome is characterized by a cluster of metabolic disorders including obesity, dyslipidemia, hyperglycemia, and hypertension [16]. It is the most common disease associated with obesity in children and adolescents and is a challenging public health problem. Besides, miRNAs have been shown to be involved in many biological processes and play a crucial role in various metabolic diseases. For example, a study confirmed that higher levels of miR-24 and lower levels of INSIG1 were also observed in nonalcoholic fatty liver disease or steatohep- atitis patients, suggesting that crosstalk between miR-24 and INSIG1 may be important for controlling lipid homeostasis in metabolic diseases [17]. Another study has shown that miR-24 has elevated abdominal adipose tissue expression levels in obese and diabetic patients [18] In our research, the results showed that the expression level of miR-24-3p was lowest in the control group and highest in obese children with metabolic syndrome, revealing its crucial role in the occurrence and development of childhood obesity. Our results are consistent with those of miR-24-3p in metabolic diseases mentioned before.

There is much debate about which obesity indicators should be used to predict metabolic syndrome [19]. BMI has been shown to be an indicator of overweight or obesity and is associated with a risk of cardiovascular disease and metabolic syndrome [20]. As well, obese individuals have increased total blood volume leading to increased workload for the heart which in turn causes hypertension and left ventricular hypertrophy. TG and FBG have been reported as useful indicators of insulin resistance [21]. In the meantime, a study of the Population of South Korea confirmed its link to diabetes [22]. In our clinical study, compared with other indicators of healthy children, BMI, TG, FBG, SBP, and DBP have higher significance in obese children and obese children with metabolic syndrome. This is consistent with our previous description of the importance of BMI, TG, FBG, SBP, and DBP in obesity and metabolic syndrome. Additionally, correlation analysis results showed that miR-24-3p was positively correlated with BMI, TG, FBG, SBP, and DBP. Regarding the aberrant expression level of miR-24-3p in diabetes, we hypothesized that miR-24-3p may play an important role in the development of childhood obesity. In view of the importance of miR-24-3p in obese and obese children with metabolic syndrome, we further used the ROC curve to predict its diagnostic ability.

There is ample evidence that obesity increases the risk of chronic diseases, such as cardiovascular disease, stroke, and cancer, and accounts for about $4.8 \%$ of global deaths [23]. It is worth noting that obesity can also cause a variety of metabolic syndromes, such as hypertension and diabetes. Among all these risk factors, obesity or body fat seems to be the main potential risk factor not only in metabolic syndrome development but also in other cardiovascular risk factors [24]. Moreover, the prevalence of obesity in China has risen sharply in recent years [25]. Numerous studies have shown that obesity, especially visceral obesity, plays an important role in elevated blood pressure [26]. Thus, accurate assessment of obesity is required for the prevention and treatment thereof [27]. Recently, obesity 
can be assessed via measurements of body fat using computed tomography, magnetic resonance imaging, DEXA, and positron emission tomography-CT8 [28]. However, the high cost and limitations of these methods make it challenging to use these models to diagnose obesity in a real clinical setting. Previous studies have demonstrated that miRNAs play important roles in mammalian development and that their dysregulation results in a wide range of human diseases. For example, miR-24-3p have been shown to play important roles in breast cancer progression and can serve as a tumor biomarker [29]. Most strikingly, miRNAs are small endogenous regulatory RNA molecules, which have emerged as potential therapeutic targets and biomarkers in metabolic syndrome [30]. For example, a study of early biomarkers of diabetes noted that miR-24-3p can be used as a candidate biomarker for diabetes and diabetes complications [31]. miR-24-3p is expressed in cardiomyocytes and endothelial cells and has been highlighted as a potential circulating biomarker [32]. In brief, miR-24-3p has a high diagnostic value in diabetes and cardio-cerebrovascular and other metabolic syndromes. It is well-known that most obesity is accompanied by metabolic dysfunction, which can lead to diabetes, hypertension, and other cardiovascular and cerebrovascular diseases. At the same time, the aforementioned study supports our results that miR-24-3p has high diagnostic value in obese children. Furthermore, serum miR-24-3p also showed high predictive value for the occurrence of metabolic syndrome in obese children. Subsequently, the logistic regression analysis further confirmed that miR$24-3 p$ is an independent factor in the development of obese children with metabolic syndrome. However, only part of the role of miR-24-3p in clinic was studied in this research. In addition, our research also has some limitations. The research population is relatively small, and a larger study population is needed to verify the current results. In the future, we can further verify its cell function and explore the specific mechanism of the role of miR-24$3 p$ in the development of obese children.
To sum up, the current study demonstrated that miR$24-3 p$ is highly expressed in obese children and obese children with metabolic syndrome. As well, this study proved that miR-24-3p has a high diagnostic value in obese children and can predict the occurrence of metabolic syndrome. The present results provide a basis for understanding the relationship of miRNAs with the occurrence and development of childhood obesity and lay a foundation for elucidating the regulatory mechanism.

\section{Statement of Ethics}

This study was approved by the Research Ethics Committee of Shengli Oilfield Central Hospital [2018045]. Subjects and legal guardians were informed of the purpose and procedure of the study, and written informed consent was obtained from legal guardians. The research was conducted ethically in accordance with the World Medical Association Declaration of Helsinki.

\section{Conflict of Interest Statement}

The authors have no conflicts of interest to declare.

\section{Funding Sources}

No fund was received.

\section{Author Contributions}

Bingjin Zhang, Lingling Xing, and Beibei Wang conceived and planned the study. Bingjin Zhang and Lingling Xing carried out the experiments and interpreted the data. Bingjin Zhang, Lingling Xing, and Beibei Wang wrote the paper. All authors read and approved the final version.

\section{Data Availability Statement}

All data generated or analyzed during this study are included in this article. Further enquiries can be directed to the corresponding author.

\section{References}

1 Vinciguerra F, Tumminia A, Baratta R, Ferro A, Alaimo S, Hagnäs M, et al. Prevalence and clinical characteristics of children and adolescents with metabolically healthy obesity: role of insulin sensitivity. Life. 2020 Jul 28;10(8).

2 Alaklabi AM, Alsharairi NA. Current evidence on vitamin $\mathrm{D}$ deficiency and metabolic syndrome in obese children: what does the evidence from Saudi Arabia tell us? Children. 2018 Jan 15;5(1).
3 Chen CL, Li H, Xing XH, Guan HS, Zhang JH, Zhao JW. Effect of TRPV1 gene mutation on bronchial asthma in children before and after treatment. Allergy Asthma Proc. 2015 MarApr;36(2):e29-36.

4 Reaven GM. Banting lecture 1988. Role of insulin resistance in human disease. Diabetes. 1988 Dec;37(12):1595-607.
5 Guo H, Ingolia NT, Weissman JS, Bartel DP. Mammalian microRNAs predominantly act to decrease target mRNA levels. Nature. 2010 Aug 12;466(7308):835-40.

6 De Felice B, Montanino C, Oliva M, Bonavita S, Di Onofrio V, Coppola C. MicroRNA expression signature in mild cognitive impairment due to Alzheimer's disease. Mol Neurobiol. 2020 Jul 31;57(11): 4408-16.
MiR-24-3p in Obese Children with Metabolic Syndrome 
7 Lu P, Wang F, Wu J, Wang C, Yan J, Li ZL, et al. Elevated serum miR-7, miR-9, miR-122, and miR-141 are noninvasive biomarkers of acute pancreatitis. Dis Markers. 2017;2017: 7293459.

8 Dong M, Ye Y, Chen Z, Xiao T, Liu W, Hu F. MicroRNA 182 is a novel negative regulator of adipogenesis by targeting CCAAT/enhancer-binding protein a. Obesity. 2020;28(8): 1467-76.

9 Garavelli S, Bruzzaniti S, Tagliabue E, Di Silvestre D, Prattichizzo F, Mozzillo E, et al. Plasma circulating miR-23 27 24 clusters correlate with the immunometabolic derangement and predict C-peptide loss in children with type 1 diabetes. Diabetologia. 2020 Dec; 63(12):2699-712.

10 Wang H, Chen F, Li J, Wang Y, Jiang C, Wang $\mathrm{Y}$, et al. Vaspin antagonizes high fat-induced bone loss in rats and promotes osteoblastic differentiation in primary rat osteoblasts through Smad-Runx2 signaling pathway. Nutr Metab. 2020;17:9.

11 Fernandez-Mendez R, Richards HK, Seeley HM, Pickard JD, Joannides AJ; UKSR Collaborators. Current epidemiology of cerebrospinal fluid shunt surgery in the UK and Ireland (2004-2013). J Neurol Neurosurg Psychiatry. 2019 Jul;90(7):747-54.

12 Bollenbach A, Schutte AE, Kruger R, Tsikas D. An ethnic comparison of arginine dimethylation and cardiometabolic factors in healthy black and white youth: the ASOS and AfricanPREDICT Studies. J Clin Med. 2020 Mar 20; $9(3)$.

13 Ji CY; Working Group on Obesity in China. Report on childhood obesity in China (1): body mass index reference for screening overweight and obesity in Chinese school-age children. Biomed Environ Sci. 2005 Dec; 18(6):390-400.

14 Taylor WC, Upchurch SL, Brosnan CA, Selwyn BJ, Nguyen TQ, Villagomez ET, et al. Features of the built environment related to physical activity friendliness and children's obesity and other risk factors. Public Health Nurs. 2014 Nov-Dec;31(6):545-55.
15 Sage AT, Holtby-Ottenhof S, Shi Y, Damjanovic S, Sharma AM, Werstuck GH. Metabolic syndrome and acute hyperglycemia are associated with endoplasmic reticulum stress in human mononuclear cells. Obesity. $2012 \mathrm{Apr}$; 20(4):748-55.

16 Wang Y, Guo X, Ma H, Lu L, Zhang R. Prokineticin-2 is associated with metabolic syndrome in a middle-aged and elderly Chinese population. Lipids Health Dis. 2016 Jan 5;15: 1.

17 Jeon TI, Osborne TF. miRNA and cholesterol homeostasis. Biochim Biophys Acta. 2016 Dec;1861(12 Pt B):2041-6.

18 Nunez Lopez YO, Garufi G, Pasarica M, Seyhan AA. Elevated and correlated expressions of miR-24, miR-30d, miR-146a, and SFRP-4 in human abdominal adipose tissue play a role in adiposity and insulin resistance. Int J Endocrinol. 2018;2018:7351902.

19 Bener A, Yousafzai MT, Darwish S, Al-Hamaq AO, Nasralla EA, Abdul-Ghani M. Obesity index that better predict metabolic syndrome: body mass index, waist circumference, waist hip ratio, or waist height ratio. J Obes. 2013; 2013:269038.

20 Grundy SM, Cleeman JI, Daniels SR, Donato KA, Eckel RH, Franklin BA, et al. Diagnosis and management of the metabolic syndrome: an American Heart Association/National Heart, Lung, and Blood Institute Scientific Statement. Circulation. 2005 Oct 25;112(17): 2735-52.

21 Du T, Yuan G, Zhang M, Zhou X, Sun X, Yu $\mathrm{X}$. Clinical usefulness of lipid ratios, visceral adiposity indicators, and the triglycerides and glucose index as risk markers of insulin resistance. Cardiovasc Diabetol. 2014 Oct 20;13: 146.

22 Lee SH, Kwon HS, Park YM, Ha HS, Jeong $\mathrm{SH}$, Yang HK, et al. Predicting the development of diabetes using the product of triglycerides and glucose: the Chungju Metabolic Disease Cohort (CMC) study. PLoS One. 2014;9(2):e90430.

23 Sundararajan S, Rabe H. Prevention of iron deficiency anemia in infants and toddlers. Pediatr Res. 2021 Jan;89(1):63-73.
24 Beydoun MA, Kuczmarski MT, Wang Y, Mason MA, Evans MK, Zonderman AB. Receiver-operating characteristics of adiposity for metabolic syndrome: the Healthy Aging in Neighborhoods of Diversity across the Life Span (HANDLS) study. Public Health Nutr. 2011 Jan;14(1):77-92.

$25 \mathrm{Wu}$ J, Xu H, He X, Yuan Y, Wang C, Sun J, et al. Six-year changes in the prevalence of obesity and obesity-related diseases in Northeastern China from 2007 to 2013. Sci Rep. 2017 Jan 27;7:41518.

26 Stabouli S, Papakatsika S, Kotsis V. The role of obesity, salt and exercise on blood pressure in children and adolescents. Expert Rev Cardiovasc Ther. 2011 Jun;9(6):753-61.

27 Chung W, Park JH, Chung HS, Yu JM, Kim DS, Moon S. Utility of the Z-score of logtransformed a body shape idex (LBSIZ) in the assessment for sarcopenic obesity and cardiovascular disease risk in the U S A. Sci Rep. 2019 Jun 26;9(1):9292.

28 Kushner RF. Clinical assessment and management of adult obesity. Circulation. 2012 Dec 11;126(24):2870-7.

29 Khodadadi-Jamayran A, Akgol-Oksuz B, Afanasyeva Y, Heguy A, Thompson M, Ray K, et al. Prognostic role of elevated mir-24-3p in breast cancer and its association with the metastatic process. Oncotarget. 2018 Feb 27; 9(16):12868-78.

30 Wade SM, McGarry T, Wade SC, Fearon U, Veale DJ. Serum MicroRNA signature as a diagnostic and therapeutic marker in patients with psoriatic arthritis. J Rheumatol. 2020 Dec 1;47(12):1760-7.

31 La Marca V, Fierabracci A. Insights into the diagnostic potential of extracellular vesicles and their miRNA signature from liquid biopsy as early biomarkers of diabetic micro/macrovascular complications. Int J Mol Sci. 2017 Sep 14;18(9).

32 Ford KL, Anwar M, Heys R, Ahmed EM, Caputo M, Game L, et al. Optimisation of laboratory methods for whole transcriptomic RNA analyses in human left ventricular biopsies and blood samples of clinical relevance. PLoS One. 2019;14(3):e0213685. 